\title{
Strategic Framework for Innovative Tourism and Sustainable Development in Namibia
}

\author{
Neeta Baporikar, Namibia University of Science and Technology, Namibia* \\ iD https://orcid.org/0000-0003-0676-9913
}

\begin{abstract}
Globally, the importance of the tourism sector for economic and sustainable development has already been acknowledged. Namibia is no exception. Endowed with natural beauty wildlife, deserts, and beautiful beaches, the tourism sector is clearly acknowledged in the development policies and plans. Despite this, there are few comprehensive studies that deal with strategic aspects of neither the tourism sector nor frameworks to enhance innovative tourism for sustainable development. Due to such precincts and lack of comprehensive research, strategic management of tourism and its development to the fullest potential is difficult. Tourism is a powerful vehicle for economic growth, and job creation is a reckoned global phenomenon. International tourist arrivals to SSA have been on the increase making it one of the fastest-growing regions in the world. Hence, adopting an exploratory approach with a systematic literature review with contextual analysis, this study aims to fill this gap and deliberates on the requisite strategic framework for innovative tourism and sustainable development in Namibia.
\end{abstract}

\section{KEYWORDS}

Approach, Culture, Development, Economic, Industry, Strategy, Tourism

\section{INTRODUCTION}

Tourism activity has a very positive impact on the development - in social and economic terms - of communities. Tourism helps the communities from all over the world to progress and it is currently one of the most important industries worldwide. Today, the business volume of tourism equals or even surpasses that of oil exports, food products or automobiles. Tourism has become one of the major players in international commerce, and represents at the same time one of the main income sources for many developing countries. This global spread of tourism in industrialised and developed states has produced economic and employment benefits in many related sectors - from construction to agriculture or telecommunications. Furthermore in the developed countries tourism plays a significant role in the economy as provider of jobs and as contributor to the GDP as well as an important agent for improving the standard of living. Thus, tourism is a powerful vehicle for economic growth and job creation all over the world. The tourism sector is directly and indirectly responsible for 8.8 percent of the world's jobs (258 million); 9.1 percent of the world's GDP (US\$6 trillion); 5.8 percent of the world's exports (US\$1.1 trillion); and 4.5 percent of the world's investment (US\$652 billion) (WTTC, 2011). The World Travel \& Tourism Council (WTTC) estimates that 3.8 million jobs (including 2.4 million indirect jobs) could be created by the tourism industry in Sub-Saharan Africa (SSA) over the 
next 10 years. The potential for growth in tourism in the region is significant and compelling. Figure 1 reflects why tourism matters for any country and economy.

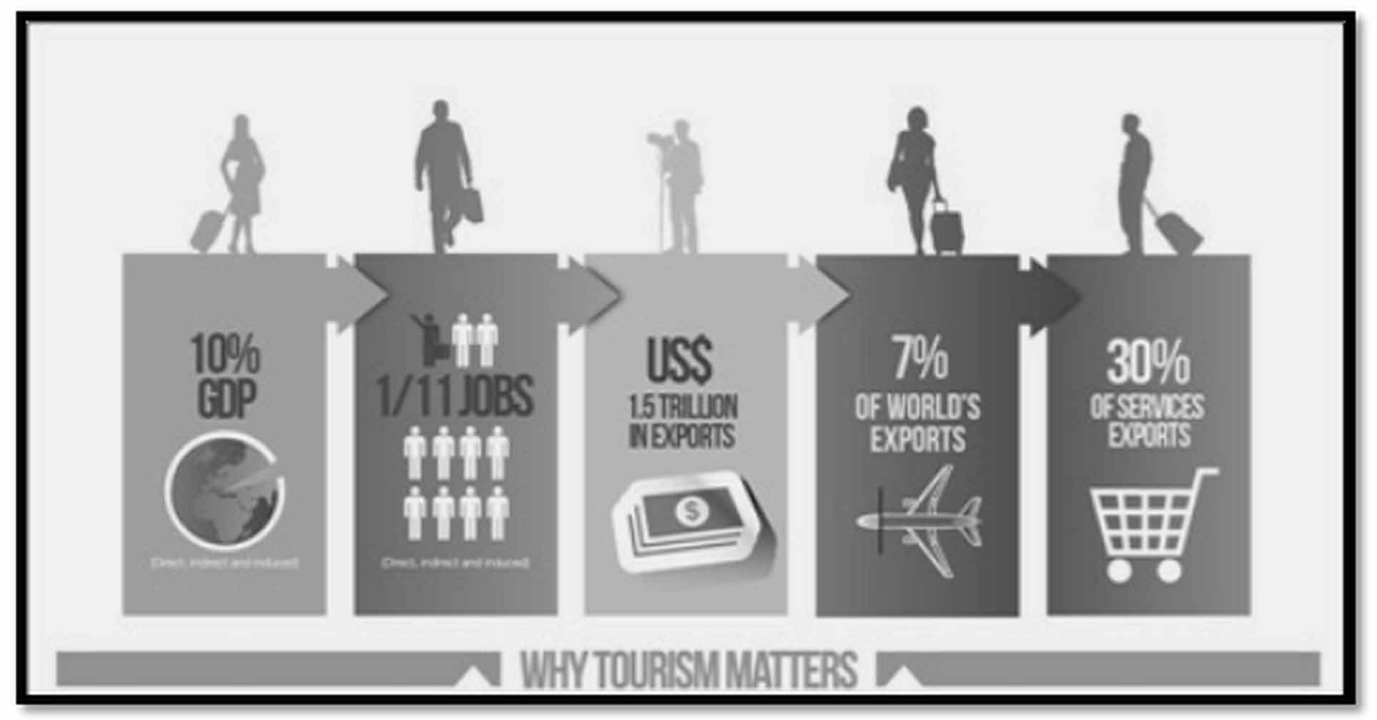

Source: UNWTO, 2016

According to Rogerson (2011), Cape Verde saw a boom in its tourism sector as a result of marketoriented policies, political and banking reforms, and investment incentives. Receipts from tourism in Cape Verde were US\$432 million in 2008, comprising 72 percent of all service exports, 15 percent of GDP, and employing directly and indirectly an estimated 21 percent of the workforce $(27,800$ people). Many other countries in SSA are on the verge of tourism success. In 2011, tourism directly generated 2.7 percent of the GDP of countries in SSA and directly and indirectly accounted for more than 1 in 20 of the region's jobs (12.8 million) (WTTC, 2012). Global hotel chains are poised to spend hundreds of millions of dollars in Africa over the next few years to meet increased demand from both international tourists and the continent's own fast-growing middle class. Global international tourist arrivals have been growing steadily at 4-5 percent per year since the 1950s. Between 2009 and 2010, despite the global financial crisis, international tourist arrivals to SSA increased by 8 percent, making SSA the second fastest growing region in the world after the Asia Pacific (UNWTO, 2010). The dramatic growth has been attributed to legislative reform, the development of a tourism strategic plan, and the elimination of visas for Southern African Development Community (SADC) countries. Already more than 10 million people are travelling across international borders every year within Africa for shopping, medical needs, sports, religious gatherings, business meetings and conferences, and visiting friends and relatives. For example, 58 percent of all arrivals to Namibia in 2010 were from South Africa and Angola. Regional arrivals to South Africa increased by 12.8 percent between 2009 and 2010 (South African Tourism, 2010).

Yet it is by no means easy to develop and sustain a successful tourism destination. African destinations compete for tourists against venues in Asia and South America. It is not enough to have interesting natural and cultural attractions and "friendly people." In many African countries a deeprooted skepticism about the economic and social benefits of tourism prevails, due to a lack of accurate 
economic data about the sector, a genuine concern about the environment, and a discomfort with foreign investors and visitors. However, tremendous amounts of resources and investments are made by both the government and the private sector in the travel and tourism industry globally. The private sector is always driven by the need to generate profits and revenue for the organization making the investments at the same time these entities are expected to practice responsible behavior and observe the laws and regulation of the region within which they conduct business and behave ethically and morally in the region. Long term planning and resource development is also essential. It does not make financial sense for anyone to build a multibillion dollar resort only to have to abandon it ten years down the road because it has not been able to maintain the integrity and environment in which the resort operates, nor, create infrastructure if they are not going to be put to optimal use. Hence, effective strategic management of tourism is crucial and need of the hour.

The importance of the tourism system for economic development in Namibia has been clearly acknowledged in the development strategies and plans. Despite the recognition of the potential significance of the tourism system for economic development there have been few detailed and comprehensive studies of the structure, dynamics and potential opportunities of tourism development. Moreover, the research that has appeared tends to be extremely narrow in sectored and/or spatial focus. This in turn renders it unhelpful in terms of a more general understanding of the strategic approach for tourism management in Namibia. In the context of such limitations and in particular the lack of detailed research covering the tourism sector as a whole, strategic management of tourism is difficult to undertake.

Nevertheless, for Namibia like many regional economies tourism can offer effective solutions to the question of regional competitiveness and regional growth. As a niche market, Namibia can respond at present to a growing demand, more and more travelers ranking wildlife, deserts and beaches and other cultural activities as one of the main reasons of traveling. This paper supports the idea that in order to be well integrated in the regional development the measures meant to improve the for tourism development at regional and local level should constitute a coherent 'package', including economic, legal, institutional, infrastructure, cultural and social elements. For this to happen there is a need to adopt as well as design strategic framework for innovative tourism and sustainable development in Namibia, Hence, adopting a exploratory approach with systematic literature review the core objective of this paper is to provide strategic framework for innovative tourism and sustainable development in Namibia. In doing so, it also highlights the current state of tourism development in Namibia and its potential contribution to regional development, considering the relatively well-balanced distribution of tourist resources on the national territory.

\section{LITERATURE REVIEW}

Tourism is of critical importance for economic development and "it is imperative to take tourism seriously and analyse it no less critically and theoretically than what are considered more legitimate topics and places" (Klak, 2007). In his study on the African tourism research landscape, Rogerson (2011) observes that the New Partnership for Africa's Development (NEPAD) in its Tourism Action Plan recognizes tourism "as one of the sectors with the most potential to contribute to the economic regeneration of the continent, particularly through the diversification of African economies and generation of foreign exchange earnings." NEPAD was adopted by the African heads of state and government of the Organization for African Unity (OAU) in 2001 and was ratified by the African Union (AU) in 2002 to address Africa's development problems within a new paradigm. NEPAD's main objectives are to reduce poverty, put Africa on a sustainable development path, halt the marginalization of Africa, and empower women.

Rogerson (2011) notes that notwithstanding the impressive growth in tourism flows to SSA during the last two decades and the policy prominence afforded tourism as a driver for economic development, the volume of academic research focused on African tourism systems has had limited 
growth, even in the benchmarking of African tourism products against global efficiency standards (Barros and Dieke 2008; Santos, Dieke, and Barros 2009; Barros, Dieke, and Santos 2010). Recent overviews of tourism scholarship in Africa in general and for the 15 countries of the Southern African Development Community (SADC) namely, Angola, Botswana, the Democratic Republic of Congo, Lesotho, Madagascar, Malawi, Mauritius, Mozambique, Namibia, the Seychelles, South Africa, Swaziland, Tanzania, Zambia, Zimbabwe, underscore the limited scholarship around the tourism-development nexus. Given the potential of tourism growth, Rogerson suggests that careful and strategic policy interventions, grounded in evidence-based research from the African experience will be essential to maximize the role of tourism in national, regional, and local development. Seif and Rivett-Carnac (2010) have called for the need "to anchor research to a canon of literature, so as to achieve greater compatibility between research sites and over time."

Conceptually, tourism investigations can employ a diverse set of theoretical frameworks because tourism is both a social and an economic activity. For Namibia to adopt a strategic approach it is better to use on the United Nations Millennium Development Goals as framework both for development and studies. The priority areas on which Namibian tourism should focus are:

- Tourism as a lever for economic growth

- Tourism's inter-sectorial linkage, human resource development and employment issues for the tourism and hospitality sector

- The implementation of tourism's pro-poor aspects to relieve poverty

- Tourism as a tool to protect the environment and cultural heritage

- The nature of the "tourist," domestic, regional and international.

- Different types of tourism versus the benefits (for example, high-end versus package holidays, community-based tourism, heritage tourism, city tourism)

The above areas need to be prioritised, which in turn would give to new voice for scholarship in tourism and hospitality. This will help to evolve better strategic framework for innovative tourism and sustainable development in Namibia which would then, have benefit of being grounded in and informed by contemporary theoretical debates and discourse.

\section{Significance of Tourism Context}

The so-called "regional problem" represents a major concern for all regional strategies and policies, being reflected by the disparities in terms of unemployment rates, population density, infrastructure, and environmental conditions, many of them being directly or indirectly related to disparities in regional welfare levels. For many regional economies tourism can bring about an encouraging response to the regional development considering its positive influence on regional employment and income. Thus, tourism generates jobs not only in its own sector but also - via indirect and induced effects - in connected sectors such as financial services, retailing and telecommunications. Tourism is an important source of new jobs in both large and small communities, representing a major industry in many regions, able to stimulate economic development and reduce economic disparities. Though, regional multipliers of tourism do not have the same magnitude in all regions: it varies in accordance with the economic, natural, social, cultural characteristics of each region (and locality). A region's size and tourist attractiveness, its industry mix in terms of specialization and concentration/diversification degree, its location, especially in relation to other local labour markets are likely to be important factors. Even more, the multipliers are not simply region-specific but also project-specific, a special attention being required in order to support those tourism projects able to generate the most important benefits to the region and to correlate them with other economic and social activities within the region (Armstrong and Taylor, 2000).

Hence, there is a need for integration of the measures which are meant to improve the frame conditions for tourism development within the regional development strategies, policies and plans. This 
implies there is a need for coherent 'package' including economic, legal, institutional, infrastructure, cultural and social elements, aiming to define a regional profile, stressing and taking advantage of the specific features of each regional or local area (Funck and Kowalski, 1997). In recent years niche markets have brought about a new perspective to developing regional tourism. The niche markets like exclusive tourism, cultural tourism, health tourism, agro-tourism, adventure/sport tourism, education tourism, aim to exploit the competitive advantages of specific market segments as a result of region's efforts to support a tourism-based competitive specialization profile. These tourism niche markets, respond to a growing demand as more and more travelers rank different reasons and activities as reasons for traveling. This is a result of social and cultural trends such as rising education levels, ageing population, increasing role of women. Recently, new trends have emerged, determining a further increase in the power of tourism, such as the choice for short, get-away trips, the growing number of young tourists, the emphasis on meaning, the increasing expectations, the impact of the internet, the desire for sustainability of both more educated tourists and local communities (Lord, 1999).

As far as niche tourism is concerned, tourists' destination choices are made in accordance with region's performance, artistic, architecture, historical offerings. Regions which do not have access to other major resources or do not have major urban centers may be able to use niche tourism approach in order to increase employment and regional income. But in a broader view, niche tourism may also encourage entrepreneurship and the development of new small businesses, particularly for people who might not have easy access to formal labour markets. From a social and cultural perspective niche tourism can improve the quality of life in an area by increasing the number of attractions, recreational opportunities and services. It also offers residents the opportunity to meet new people, experience different cultures broaden horizons, increase the insight and appreciation for different approaches to living (Galdini, 2005). On the other side, the interest of tourists provides opportunities to support and contributes to sustainable tourism principles.

\section{Rationale for Tourism Focus}

There are new grounds for optimism for the economic future of Africa. Until the onset of the global economic crisis, GDP growth had averaged 5 percent a year for a decade (World Bank, 2011). Growth was widespread even among non-oil-exporting countries and countries that experienced conflict. Although Africa was badly hit by the global crisis, the continent avoided worse growth shortfall in 2009 thanks to prudent macroeconomic policies and financial support from multilateral agencies; it rebounded in 2010. Sub-Saharan Africa (SSA) countries' poverty rate declined from 59 percent in 1995 to 50 percent in 2005 (World Bank, 2010a). Child mortality rates are declining, HIV/AIDS is stabilizing and primary education completion rates are rising faster in than elsewhere. Africa's private sector is increasingly attracting investment with much of the funding coming from the United States and Europe. China, India and other countries are also investing large sums. Private capital flows are higher than official development assistance and foreign direct investment is higher than in India. Returns to investment in Africa are among the highest in the world. The public sector has set the conditions for the exponential growth of information and communications technology (ICT), which could transform the continent. The private sector is creating an emerging middle class of hundreds of millions of consumers. The climate for market oriented, pro-poor reforms are proving robust and the voice of civil society is increasingly heard. Interregional cooperation is strengthening and democracy has taken hold in several countries. Given this scenario, experts view Africa as being on the brink of an economic take off, much like China was 30 years ago, and India was 20 years ago. Tourism is one of the key industries driving the change. From a small base of just 6.7 million visitors in 1990, SSA attracted 33.1 million visitors in 2011 (UNWTO, 2012). Tourism contributed US $\$ 33.5$ billion to the economies of SSA, accounting for 2.7 percent of the region's GDP (WTTC, 2012). Already 1 in 20 jobs is in travel and tourism. New analysis indicates that women manage about 50 percent of hospitality businesses in Africa (UNWTO, 2011). Tourism provides multiple opportunities for economic growth and improved livelihoods. 


\section{Profile of Namibia}

Namibia covers 824,292 sq. $\mathrm{km}(318,259$ sq. mi) and is located on the south western coast of Africa, Namibia borders Angola and Zambia in the north, South Africa in the south and Botswana in the east. Part of the allure of Namibia is that its four countries in one, four different landscapes, each with its own characteristics and attractions. The most definitive is the Namib, a long coastal desert that runs the length of the country and is highlighted with migrating dune belts, dry riverbeds and canyons. The central plateau is home the majority of Namibia towns and villages and is divided between rugged mountain ranges and sand-filled valleys. Next is the vast Kalahari Desert with its ancient red sand and sparse vegetation. Finally, Kavango and Caprivi blessed with generous amounts of rain and typified by tropical forests, perennial rivers and woodland savannahs. Namibia is truly unique, influenced by various cultures during colonization and now reborn from the shadows of Apartheid in 1990. What has emerged is a true sense of unity in diversity, the coming together of at least 10 major ethnic groups consisting of: Kavango, Damara, Herero, Himba, Nama, Owambo, San, Tswanas and Whites. Each of these ethnic groups celebrates their past with individual flavour while works together toward the future. This can be noticed in dress, language, art, music, sport, food and religion, but there exists a wonderful collage, but first and foremost, Namibians are proud to be Namibian and for good reason.

\section{Reasons for Developing Tourism in Namibia}

Tourism often does not receive the credit it deserves as an economic transformer. Yet the evidence from Thailand, where tourism accounts for 6 percent of GDP, to Mauritius and Cape Verde, where it accounts for 13 percent and 15 percent of GDP, respectively, tells a different story and underlines the sector's potential. The prime reasons for developing tourist assets and poising a country for sustained economic growth of its tourism sector are:

1. Energize economic transformation: The global tourism sector is vast and still growing. In 2010, 935 million tourists travelled internationally. They spent US\$339 billion directly in emerging economies. The total global export income from tourism was over US $\$ 1$ trillion. The average annual growth rate in international tourist arrivals from 1995 to 2010 was 4.1 percent (UNWTO, 2010). The total direct, indirect and induced impact of travel and tourism on global GDP in 2011 was estimated at US\$6.3 trillion, with 255 million jobs in the sector, US\$743 billion in investments and US $\$ 1.2$ trillion in exports. Tourism's contribution in 2011 represented 9 percent of global GDP, 1 in 12 jobs, 5 percent of investment and 5 percent of exports. Growth forecasts for 2012, although lower than originally anticipated, should still see tourism contributing 2.8 percent of total GDP (WTTC, 2011). Tourism has demonstrated its economic strength and potential all over the world. In Thailand, tourism barely existed in the 1960s; in 2010 it was worth 6 percent of GDP and employed 15-20 percent of the workforce. Thailand is not the only tourism success story. The Dominican Republic, in the Caribbean, had only 1,600 hotel rooms in 1972 but in 2011 had over 66,000; tourism accounts for 31 percent of exports of goods and services, and 7.9 percent of GDP. Bali, a small island in Indonesia, received 95,000 international tourists in 1973; in 2010, Bali attracted 1.96 million tourists who spent US\$1.9 billion. Cancún in Mexico grew from an uninhabited peninsula to one of the most visited resorts in the world in just 35 years: Cancún now has over 600,000 residents and hosts over 10 million tourists a year. Its success is attributable to: the government's foresight in imagining a grand resort on a deserted peninsula as part of its long-term strategy for economic development, proximity to a very large and wealthy market in North America, its Caribbean climate and beach assets and help from Spanish hotel groups skilled in offering all inclusive vacations. Similar patterns of growth occurred in Egypt. In 1970, Egypt attracted fewer than 400,000 tourists; by 1980 the number had reached 1 million. From 1990 to 2005, visitor arrivals grew from 2.9 million to 8.6 million; by 2010 total international arrivals amounted to just under 15 million and tourist expenditures reached US $\$ 12.5$ billion. 
Tourism has accounted for 9.1 percent of Egypt's GDP and has traditionally been the country's largest foreign exchange earner, ahead of worker remittances and petroleum products. According to the WTTC, total direct and indirect employment in the sector amounts to 3.35 million jobs.

2. Employment Generation: Currently, more than 200 million people are underemployed in SubSaharan Africa and 10 million more seek jobs every year (World Bank, 2010b). As tourism grows, the sector's job creation and income-generating potential rise exponentially (Natural Resources Consultative Forum, 2007). Tourism compares well to other sectors in terms of opportunities for SME development, career advancement, and lifelong learning potential. One in 20 jobs in SSA is already in travel and tourism (Twining-Ward, 2010a). Tourism is also a more efficient job creator than many other sectors due to the multiple downstream effects. A study in Zambia by the Natural Resources Consultative Forum found that a US\$250,000 investment in the tourism sector generates 182 full-time formal jobs. This is nearly 40 percent more than the same investment in agriculture and over 50 percent more than in mining (Hamilton at el, 2007).

3. Overall regional development: Tourism is growing faster in the world's emerging and developing regions than in the rest of the world. International arrivals in developing countries increased by an average of 11 percent a year between 1990 and 2009 (UNDP, 2011). The share of international tourist arrivals received by emerging and developing regions increased from 32 percent in 1990 to 47 percent in 2010 (UNWTO, 2010).

4. Accelerates reforms: Tourism accelerates policy and economic reforms that can help SME development and stimulate foreign investment (Wong, Christie, and Al Rowais, 2009). In Cape Verde, tourism took off when the banking sector was reformed, when the escudo was pegged to the euro, and when an attractive package of investment incentives was created (Twining-Ward, 2010b). In Rwanda, significant improvements in "doing business" indicators were linked to the desire to increase gorilla tourism. Across SSA, destinations are finding that political stability, good governance, and an enabling business environment provide the foundation for tourism growth (UNCTAD, 2007).

5. Activates infrastructure developments: In an effort to attract visitors, governments and private sector business people often invest in infrastructure improvements that have positive impacts on the economy and on rural communities. South Africa invested US $\$ 2.6$ billion in upgrading the Johannesburg, Cape Town, and Durban airports in preparation for an influx of sports tourists for the 2010 FIFA World Cup (Agence Française de Développement, 2010). For some years hotel managers worldwide have reached out to their surrounding communities to improve the health and welfare of their workers but also to ensure that local people prize the benefits that tourists can bring them, thus protecting tourists from potential resentment from the much poorer local people. In addition, tourists are generally willing to donate money to help local communities. Sun 'n' Sand Beach Resort in Kenya provided water and a health clinic for a neighbouring village. The Nihiwatu ecolodge in Sumba, Indonesia, raises US\$400,000 annually to help 147 villages with health, clean water, and nutrition projects.

6. Increases domestic consumption and diversifies exports: Tourists create demand for nontourism goods and services such as transport, gasoline, retailing, finance, real estate, agriculture, and communications. The WTTC expected tourism to generate twice as much from indirect spending on nontourism goods and services and from induced supply chain benefits, than from direct tourist spending in 2011 (WTTC, 2011).

7. Empower women, young people, and marginalized populations: Women make up an estimated 70 percent of the world's poor (ILO, 2009). Empowering women to participate in economic development at all levels and in all sectors is essential to build strong economies and stable, just societies (UNIFEM and UN Global Compact, 2010). Tourism is one of the few economic sectors in which women outnumber men in certain positions and are paid the same. In Africa, a 2010 study by UNWTO and UN Women found that 31 percent of employees in the hotel and restaurant sector were women (Twining-Ward, 2011), compared to 21 percent in other sectors. 
Young people also derive productive employment from tourism. In Namibia, after just one year of training, an unskilled labourer can learn to be a tour guide and thereby increase his or her income significantly. By engaging young people in productive employment, tourism can provide an alternative to out-migration, urban poverty, and armed conflict.

8. Inspires cultural heritage and environmental conservation: Tourism creates additional value for historic buildings, heritage sites, and the fine and performing arts (Robinson and Picard 2006; World Bank, 2001). Cultural heritage is under threat across SSA but tourism provides a revenue source for its protection. In Ethiopia, for example, the World Bank helped finance a US $\$ 35$ million cultural heritage project in 2010 that supports and complements private sector investment at major heritage sites and their surrounding communities through tourism planning. Tourism also provides a stimulus for environmental conservation and promoting alternative livelihoods. In 2008, a partnership between the UNDP Global Environment Facility (GEF) and the government of the Seychelles established a US\$3.6 million, six-year biodiversity management project. In Costa Rica, the decision to promote sustainable tourism led to the establishment of a broad spectrum of environmental and social initiatives, including the Costa Rica Certificate in Sustainable Tourism and Blue Flag Beaches.

9. Promotes public-private partnerships: Effective tourism planning requires collaboration and partnerships between public and private sectors. Consultation enables participants to take joint responsibility for policy choices, facilitates the collection of economic data, and has positive outcomes for national planning. Public-private partnerships (PPPs) in conservation, infrastructure development, and investment promotion have been used for many years in SSA. Examples include the approach taken by Kenya Wildlife Service, SANParks in South Africa, the Madagascar National Parks Initiative, and Gorongosa National Park in Mozambique (Garcia 2010). The WWF reports that more than US\$19 million has been invested by the private sector in tourism joint ventures in communal conservancies in Namibia since 1998 (NASCO, 2009).

10. Constructs and promotes brand building of a national: Successful tourism can change external perceptions of a country, improve intercultural understanding, and create a positive internal frame of reference for a country. Once war-torn, Rwanda has changed its image because it features mountain gorilla conservation and tourism. Civil strife is in Mozambique's past; it is now known as a country with attractive beach resorts. Costa Rica is associated with biodiversity, ecotourism, and environmental consciousness, rather than with the drug trafficking that plagues other countries in the vicinity. The advent of satisfied tourists' increases national pride, enhances investor confidence, and serves as an engine of growth for the economy as a whole.

\section{Strategy Development Principles}

The guiding principles for the development of the strategy and the future management of the industry's development are widely accepted and based on the following core beliefs:

- Sustainable Tourism: The worldwide acceptance of this concept is an essential principle of all future tourism development. The future management of natural, man-made and human assets is critically important for the long-term sustainability of any tourism industry in general and Oman in particular. Developments which adversely impact the environment, which are short-term, high volume, and opportunistic in nature should be avoided. Key aspects of a sustainable tourism policy include land use; management of the physical environment; conservation of natural and cultural heritage sites; development of market led products; and investment in human resources.

- Profitability: The tourism industry in Namibia has had poor investment returns for many years and only in the past decade - particularly the latter half - has there been a welcome rise in profitability. Businesses must derive an adequate profit to ensure continued expansion through investment. Profitability needs to be improved through increased utilization of the assets within 
the sector - for example increased occupancy rates of accommodation providers or more visitors through an attraction. Profitability can be assisted through the introduction of greater efficiencies - for example co-operative marketing, or through ensuring that increases in volume sales are not achieved on low price competition strategies.

- Selective Investment: Future investment strategies will need to be highly selective and clearly targeted. In an area where there has been substantial investment by both the public and private sector and where there is currently more taking place, care must be exercised in the direction and scope of what is to follow. So too is the issue of comparison with investment priorities across the Border where differing regimes may be in place and where duplication of effort is possible. Identifying clear market gaps is essential.

- Targeted Marketing: It must be stated that this has to be a clear guiding principle, although it is necessary to point out that this principle is demonstrably already in place. However, complacency should be avoided especially as fast changing delivery mechanisms become the norm, through the continual change in IT capabilities. The choice of markets, products and segments for the future must not be assumed to be as it is today. A continuous review process is necessary to determine the appropriateness of the products in the area and the type of tourism sought. The rate of change elsewhere may render a product obsolete much more quickly than the provider thinks. An outward looking industry well informed of trends and new products is essential for future success.

- Public Private Sector Partnership: It is generally recognized in the tourism world that successful destinations are those where a partnership has been built up between the public and private sectors. Partnership may however need to extend beyond marketing and into strategic planning / development issues. It may also need to develop a more effective two way process to ensure that the balance of risk does not seem to lie disproportionately on any side - public or private.

\section{Strategic Action Key Areas}

To achieve a substantial and sustainable increase in tourism revenue which reflects the above guiding principles, there is a need to take strategic action in five key areas. They are:

- Product development: To ensure the continued development of the range of 'attractors' within the area and provide new 'things to do' for the visitor. Much of the effort in this will be focused into improving the existing attractions to make them accessible and to fulfill their tourism role as magnets for the area. Some accommodation work will also be required.

- Marketing: To continue to develop the destination marketing capacity and other support agencies to ensure that best practice continues, while implementing changes that an All Oman approach may require. Beyond destination marketing lays the need for the existing attractions to devote the appropriate effort and budget to undertaking their own marketing role.

- Quality assurance: To ensure that the quality of the product delivered lives up to the expectations of the visitor. In a world that is so competitive for tourism this becomes increasingly important. This is true of the public, private and voluntary sectors and embraces issues ranging from signposting, to litter, to unhelpful staff and to opening hours. This is an important issue in the delivery of tourism growth in a sub-region surrounded by high quality competition.

- Management and co-ordination: Though the achievements of the Ministry of Tourism have been notable and substantial, there is however a gap in the tourism delivery mechanism, in that the development role in tourism must be addressed. The links with other agencies and new departments are now more complex than ever and therefore co-ordination for tourism must be given a higher priority and resource.

- Motivating Tourism: Tourist motivation can be defined "as the global integrating network of biological and cultural forces which gives value and direction to travel choices, behaviour 
and experience". (Pearce, Morrison \& Rutledge, 1998) as cited by Allan R. Rhodes Espinoza. According to Seaton (1997) motivation is a state of arousal of a drive or need which impels people to activity in pursuit of goals. Krippendorf (1987), as cited in Seaton (1997) suggests that the motivation of the individual person to travel, to look outside for what he cannot find inside have been largely created by society and shaped by everyday life. People who live in cities, for example, are motivated to travel as tourists to wilderness areas because they need to escape from an artificial, monotonous environment. (Dann \& Matley, 1976) as cited in Mansfeld, 1992). An understanding of the various types of tourism purpose and motivation is vital for those planning and marketing tourist destinations. Seaton (1997) says that all tourism planners must know why people want their products. Seaton (1997) typifies two such sets of opposing desires: Novelty and adventure (exploring a new place) vs. Familiarity and security (staying in a hotel with familiar comforts). Another problem is that it is often difficult to distinguish individual motives from socially constructed vocabularies of motives. People often give reasons for doing things that they have been programmed to give, none of which may constitute the real reason for a trip. According to Page (2003), if we are able to understand what prompts people to leave their homes and travel to new places, then we may be able to develop approaches that will help us to manage the tourists and their impacts and plan an enjoyable experience for them. More fundamentally, understanding tourist motivation may help to explain why certain places, countries are more developed as successful tourism destination than others and continued to grow and do better and better.

\section{Key Features of Tourism}

- Tourism is a commercial activity: Businesses enter the tourism sector to profit from those who travel. States and provinces advance tourism because it generates new money for their jurisdictions. Whilst the tourist travels to satisfy inner needs such as escape, rest, recreation, status, or learning, the product providers aim at profits. Tourism is unique in that the bulk of revenue is generated by facilitators of experiences rather than by experience providers. The tourism industry enables tourists to 'consume' experiences, but does not necessarily provide the experiences themselves. Indeed, only a small fraction of the cost of a tour is spent at what can be termed designated attractions; the rest is spent on transport, accommodation, food, drink, tips, sightseeing and commissions to the travel trade. Yet, it is the attractions that draw tourists to a region in the first place, enabling the rest of the benefits to accrue.

- Tourism involves the consumption of experiences: Tourists satisfy their personal needs by experiencing enjoyable activities - tourism is thus a form of consumption. Unlike most other economic activities that enjoy a virtually exclusive hegemony over the use or consumption of their resources, tourism resources are typically part of the public domain or are intrinsically linked to the social fabric of the host community.

- Tourism is entertainment: Tourism experiences, especially the culturally - or event-centered variety, have their bases in entertainment. To be successful, and therefore commercially viable, the tourism product must be manipulated and packaged in such a way that it can be easily accessed by the public. Tight tour schedules, limited 'time budgets' and the need to process large numbers of visitors mean that the product must often be regulated to match fixed 'consumption times' in order for the experience to be a guaranteed one.

- Tourism has both positive and negative effects: One of the great myths promoted by sector tourism agencies and NGOs is that by controlling supply, the adverse impacts of tourism can be controlled. Although this may be true at an operational level where undesirable elements can be refused entry or forcibly removed, the global history of rampant tourism development, even under a supply-driven approach, illustrates that this policy rarely works on a regional or national basis. "The great challenge for any destination is to control the genie of tourism once 
it is let out of its bottle." The history of spontaneous development and the resultant social and environmental costs associated with it attest to the challenge faced by any destination that seeks to promote tourism. The best that governments can do is hope to influence the direction tourism will take.

- Tourism is a demand-driven activity that is difficult to control: Tourism is fundamentally a demand-driven activity that is influenced more by market forces (tourists and the industry that seeks to satisfy tourists' needs), rather than by governments that try to control or manage it. Tourism, tourists and the industry itself behave in a manner similar to a bottom-up, self-organizing, living ecosystem that cannot be controlled using traditional supply systems. Further, it has been the experience of many researchers that advocates of supply-side controlled tourism are often elitist in their attitudes. They assert that encouraging the 'right type' of development will attract the 'right type' of provider, which will appeal to the 'right' travel distributor who will reach the 'right type' of tourist. This person is usually posited as an affluent experienced traveler who is aware of and sensitive to local culture, its heritage and natural ecosystems, and who will want to stay in local accommodation, eat locally produced food, and be content with very basic facilities - all this while paying high tariffs. The problem is that this type of person represents only a tiny portion of the traveling public. How does one satisfy the needs of the vast majority of tourists, those who do not fit this ideal description? They are not going to stop traveling: they will continue to make demands for affordable services and facilities.

\section{RECOMMENDATIONS}

From the above, it is clear that there is ample scope for development of sustainable tourism and related industries in Namibia. The growth in the Tourism and Hospitality industries has been good in the past few years since Namibia is an attractive tourist destination apart from being safe for tourists. However, to accelerate the expansion and provide further impetus to tourism sector the following are the recommendations:

- Awareness among the citizens especially in the interior places need be created.

- Develop basic infrastructure and amenities in the tourist spots, proper location maps and road pointers including road signs need to be there on highways and junctions to facilitate travellers.

- Good and decent restaurants of varying price range to cater to all classes of tourists serving authentic Namibian food need to be developed.

- Expose youth to tourism aspects at schools so that they can seek career opportunities in Tourism and Hospitality sector in future.

- The support sectors like local transport, foreign exchange facilities, tourist guidance centres etc. should also be well developed otherwise these will have a negative impact on tourism sector if the quality of support service is not maintained.

- Namibia has great opportunity and vast potential to be a prime tourist destination, a development that would significantly grow the emerging economy. To date, though, the tourist potential is largely untapped and hampered by improper focus and lack of planning. But there is movement afoot to change this situation.

Figure 2 gives the proposed strategic framework for tourism development in Namibia.

Namibia should set out to aggressively and strategically promote the nation's riches in cultural attractions through various communications mediums reaching external audiences (strategic marketing). Moreover, because the population in certain nations or regions will have greater affinity or interest in traveling to Namibia - for various reasons - the strategic marketing efforts should focus particularly on reaching these markets (international and regional markets promotion). If long-term tourism policy is to be successful, there is a need to re think. A more strategic approach for tourism 


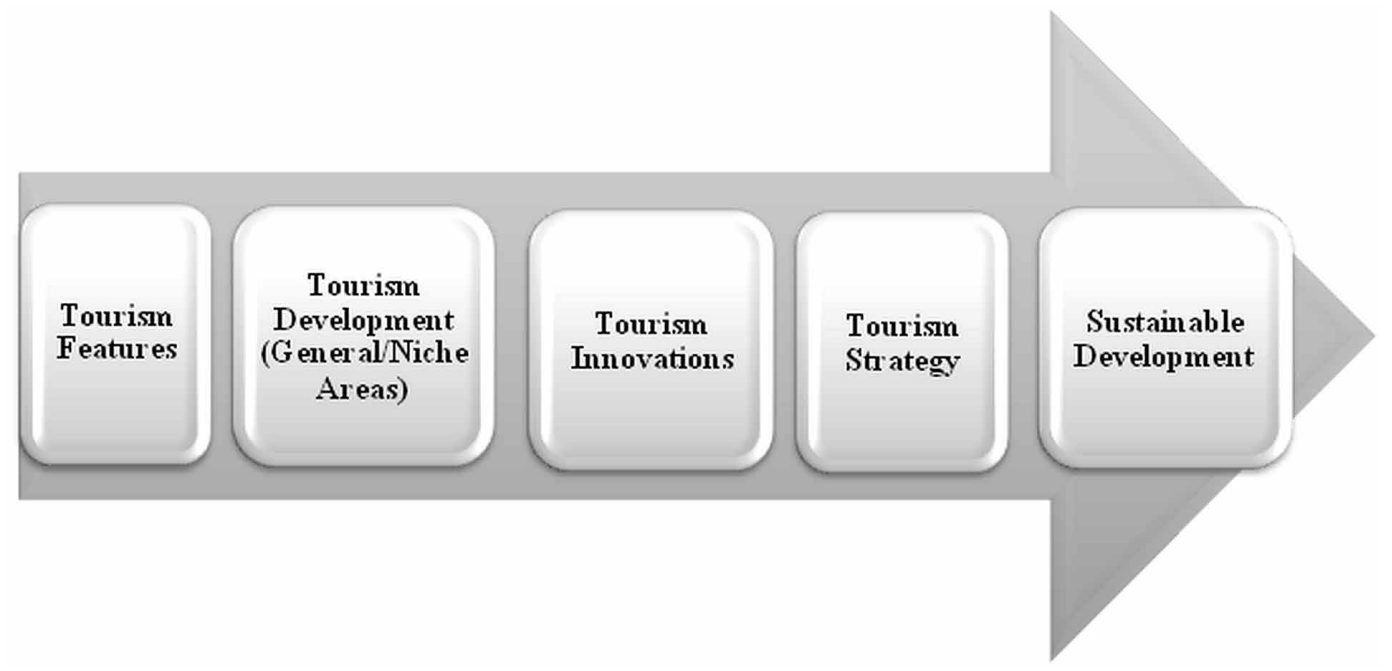

development is required and instead of more beachfronts being utilized to accommodate large resorts, the investments in tourism should come from within. The government has the opportunity to team up with the banks and help finance and underwrite smaller and locally driven tourism projects. In our view, the smaller projects will have a less destructive impact on our environment and will also spread the benefits of tourism to all parts of the country thus giving rise to a local supply and demand chain, a vital ingredient for job creation which will help to achieve the goal of nationalization in the real sense. Further to ensure sustained growth and be innovative, a special role in the implementation phase has to be played by regional/local public administration, which is the most appropriate level for ensuring the necessary operational convergence between the national level and local communities, between various public and private stakeholders involved in defining and creating the tourist supply, with a special emphasis on sustainability aspects (Galdini, 2005). It has to adapt its view on tourism development so as to widen and enrich the traditional approach to regional economy, planning and sustainability based on a framework able to take into consideration and to integrate general economic policies, socio-economic development requirements and cultural challenges.

\section{FUTURE RESEARCH DIRECTIONS}

Tourism today is much more than just developing products. It is more about quality, insightful thinking and ability to have global information about technology, partners, contacts and responding quickly to global and regional trends. Tourism should be a vehicle for international cooperation and understanding various civilizations and a harbinger of peace. Studies on these issues are essential in the Namibian context. There is also the need for proper training of the personnel working in the industry, hence research on human resources training and development is another critical area as tourism is service industry heavily dependent on trained personnel. The lack of adequate research on tourism entrepreneurship is also a major handicap and there is not much literature about the role of entrepreneurs in tourism. Studies need to be undertaken especially to highlight the gap in our understanding of how small medium tourism establishments (SMTEs) in destinations influence overall economic development. Research is also required as a process to inform public sector decisionmaking to promote tourism with Namibia as an investment decision to assist localities in building a service economy. Studies to provide the blueprint or strategic direction for change, along with 
potential business opportunities hence become essential. The tourism entrepreneurs are mainly in the business of travel agents, tour organizers and operators, hospitality and handicrafts and the role they play significantly fuel the growth of tourism (Baporikar, 2018; Baporikar, \& Sokhalingam, 2012). Hence, research on tourism entrepreneurs will help to have better understanding of its progress and potential. The contribution made by these entrepreneurs is tremendous and there is need to assess and acknowledge it as such research findings will motivate and educate the budding entrepreneurs to be successful and promote tourism and the economy of the nation.

\section{CONCLUSION}

The impact and consequences of tourism cannot be prevented, and, unfortunately, besides the positive impacts, the tourism activity might also cause negative impacts on the local community, on the environment and even on the tourism destination itself (Brian, Cooper, Ruhanen, 2005). Therefore, the tourism activity needs to be planned and managed with a strategic framework to minimize these negative impacts and accentuating the positive impacts. Unfortunately, one characteristic of the impacts caused by the tourism activity is that they are multi-faceted, and therefore, difficult to plan for and manage needs to be understood and dealt in a innovative and sustainable manner. Further, tourism sector is fragmented into many industries like Travel, Hospitality, Transportation, Tour guiding, Handicrafts etc. Tourism in the modern world has grown to be one of the largest industries in the world and as per the World Travel \& Tourism Council (WTTC) and World Economic Forum (WEF); it generates ten percent of global GDP and employment (Lahiri, 2005). The nature of tourism development requires both public and private sectors active participation. Additionally, if long-term tourism policy is to be successful, there is a need to re think. A more strategic approach for tourism development which is inclusive is required (Baporikar \& Sokhalingam, 2010). The government has the opportunity to team up with the banks and help finance and underwrite smaller and locally driven tourism projects, which will have a less destructive impact on our environment and will also spread the benefits of tourism to all parts of the country thus giving rise to a local supply and demand chain, a vital ingredient for job creation which will help to achieve the goal of nationalization in the real sense (Sokhalingam \& Baporikar, 2011; 2012).

Today, travel and tourism has become part of the people's regular activity, for the economies worldwide the sector generates not only revenues but is also a great provider of employment (Baporikar, 2011). Namibia, is also rightly eying the tourism development as a means for economic development. However, the tourism industry in Namibia is comparatively new as majority of tourists in Namibia are from other SAA countries. It is also relatively small part of the total economy but has been growing quite rapidly. The exploration of a tourism development strategy is dependent upon a number of different inputs. These include the institutional environment in which tourism enterprises function, the profile of the tourists in terms of personal characteristics and associated tourism needs and desires, and tourism products on offer. However, one cannot afford to ignore the impact of tourism on hospitality industry which will have a snowball effect for generation employment for locals. This in turn calls for further strengthening tourism education and training. Hence, the tourism sector will need to carefully chalk out its strategy and be adaptable to the demands of the evolving global economy. To conclude, the tourism vision of Namibia for 2025 should be to "create a vibrant international tourist city set in an attractive environment, embracing also a vibrant river and rural area, all with a welcoming user-friendly tourism infrastructure". This vision embraces a holistic perspective towards tourism development and a well-managed environment coupled with a variety of new and refreshed products, delivered by enthusiastic and well-trained staff, giving good value for money would go a long way in putting Namibia on the international tourism map of the world.

To conclude, this paper makes an effort to have a holistic understanding of tourism, its growth in Namibia and delves into the need for a strategic framework for innovative tourism and sustainable development of tourism sector. The tourism sector provides opportunities for young entrepreneurs 
and also successful tourism can change external perceptions of a country, improve intercultural understanding, international business and create a positive frame of reference for a country (Baporikar, $2015 ; 2012)$. It is also hoped that, it will help the authorities to frame policy decision, encourage and support innovative entrepreneurs and develop the tourism sector which would go a long way in nation building and development (Baporikar, 2014). Hence, the smaller projects will have a less destructive impact on our environment and will also spread the benefits of tourism to all parts of the country thus giving rise to a local supply and demand chain, a vital ingredient for job creation and also help to achieve the goal of entrepreneurship development in Namibia. 


\section{REFERENCES}

Archer, B., Cooper, C., \& Ruhanen, L. (2005). The positive and negative impacts of tourism. Global Tourism, 3, 79-102.

Armstrong, H., Taylor, J., \& Taylor, J. (2000). Regional economics and policy. Academic Press.

Baporikar, N. (2012). Emerging Trends in Tourism Industry in Oman. In P. Ordóñez de Pablos, R. Tennyson, \& J. Zhao (Eds.), Global Hospitality and Tourism Management Technologies (pp. 116-135). IGI Global. doi:10.4018/978-1-61350-041-5.ch008

Baporikar, N. (2014). Innovation Strategies in SME: Global Perspective. In C. Machado \& P. Melo (Eds.), Effective Human Resources Management in Small and Medium Enterprises: Global Perspectives (pp. 315-341). IGI Global. doi:10.4018/978-1-4666-4731-2.ch016

Baporikar, N. (2015). Effect of National Culture on Development of International Business in the Sultanate of Oman. In Handbook of Research on Global Business Opportunities. Business Science Reference.

Baporikar, N. (2018). Contemporary Perspectives on Women Entrepreneurship in India. In D. Chitakunye \& A. Takhar (Eds.), Examining the Role of Women Entrepreneurs in Emerging Economies (pp. 186-211). IGI Global. doi:10.4018/978-1-5225-5112-6.ch009

Baporikar, N., \& Sokhalingam, C. P. (2010). Strategic Management of Tourism - A Case of Oman (1st ed.). VDM Verlag.

Baporikar, N., \& Sokhalingam, C. P. (2012). Holistic Approach to Tourism Entrepreneurship: A Case of Tamil Nadu. International Journal of Tourism and Travel, 5, 57-66.

Barros, C. P., \& Dieke, P. U. C. (2008). Technical Efficiency of African Hotels. International Journal of Hospitality Management, 27(3), 438-447. doi:10.1016/j.ijhm.2007.11.004

Briedenhann, J., \& Wickens, E. (2004, February). Tourism routes as a tool for the economic development of rural areas - vibrant hope or impossible dream? Tourism Management, 25(1), 71-79. doi:10.1016/S02615177(03)00063-3

Chhetri, P., Arrowsmith, C., \& Jackson, M. (2004). Determining hiking experiences in nature-based tourist destinations. Tourism Management, 25(1), 31-43. doi:10.1016/S0261-5177(03)00057-8

Cluster Consortium. (1999). The South African Tourism Cluster: Strategy in Action (Unpublished report). Tourism Clustering Initiative, Johannesburg.

Dieke, P. U. C., \& Santos, C. M.Cluster Consortium (2010). Heterogeneous Technical Efficiency of Hotels in Luanda, Angola. Tourism Economics, 16(1), 137-151. doi:10.5367/000000010790872178

Collier, A. (1989). Principles of Tourism. Pitman.

Department of Environmental Affairs and Tourism (DEAT). (2004). Domestic Tourism Growth Strategy 2004 to 2007. Department of Environmental Affairs and Tourism.

Ernst and Young. (2010). Sub Saharan Africa Hospitality Sector Overview. World Bank.

Funck, R. H., \& Kowalski, J. S. (1997). Innovative behaviour, R\&D development activities and technology policies in countries in transition: The case of Central Europe. In Innovative behaviour in space and time (pp. 408-430). Springer. doi:10.1007/978-3-642-60720-2_20

Galdini, R. (2005). Structural Changes in the Tourist Industry. Academic Press.

Janiskee, R. L. (1996). Historic houses and special events. Annals of Tourism Research, 23(2), 398-414. doi:10.1016/0160-7383(95)00069-0

Klak, T. (2007). Sustainable ecotourism development in Central America and the Caribbean: Review of debates and conceptual reformulation. Geography Compass, 1(5), 1037-1057. doi:10.1111/j.1749-8198.2007.00055.x

Lahiri, K. (2005). Tourism and Hospitality Services an Introduction. The ICFAI University Press. 
Lord, G. D. (1999, September). The power of cultural tourism. In Keynote Presentation, Wisconsin Heritage Tourism Conference (Vol. 17, No. 9, p. 1999). Academic Press.

McKercher, B., \& Du Cros, H. (2002). Cultural tourism: the partnership between tourism and cultural heritage management. The Haworth Hospitality Press.

Melian-Gonzalez, A., \& Garcia-Falcon, J. M. (2003). Competitive potential of tourism in destinations. Annals of Tourism Research, 30(3), 720-740. doi:10.1016/S0160-7383(03)00047-1

Rogerson, C. M. (2002). Driving developmental tourism in South Africa. Africa Insight, 32(3), 33-42. doi:10.4314/ai.v32i3.22275

Rogerson, C. M. (2011). The African Tourism Research Landscape: Current Directions and Gaps. Paper presented to an Expert Panel workshop for Aga Khan University, Nairobi, Kenya.

Santos, C. M., Dieke, P. U. C., \& Barros, C. P. (2009). Efficiency Measurement Systems in Hotels: Perspectives from Luanda, Angola. Tourism Review International, 12(3/4), 303-315.

Seif, J., \& Rivett-Carnac, K. (2010). Editorial: Tourism Impacts: Lessons for policy, programmes and projects. Development Southern Africa, 27(5), 627-628. doi:10.1080/0376835X.2010.522825

Sharpley, R., \& Telfer, D. J. (2002). Tourism and development: concepts and issues. Channelview Publications.

SH\&E. (2010). Competitive Africa: Tourism Industry Research Phase II Air Transport Sector Study. World Bank.

Sokhalingam, C. P., \& Baporikar, N. (2011). Tourism Entrepreneurship in Tamil Nadu - A Case of Inclusive Approach, Matrix. Business Review (Federal Reserve Bank of Philadelphia), 1(2), 16-26.

The Tourism Blueprint. (1997). South Africa's Free State: A Tourism Blueprint Travel Guide 1997/1998. The Tourism Blueprint, Millerton.

Urban-Econ. (2004). Free State Economic Profile. Urban-Econ Development Economists.

Wilson, S., Fesenmaier, D. R., \& Van Es, J. C. (2001). Factors for success in rural tourism development. Journal of Travel Research, 40(11), 132-138.

World Tourism Organization. (1980). Physical planning and area development for tourism in the Six WTO regions. WTO.

World Tourism Organization. (1999). International tourism: A global perspective. WTO.

Neeta Baporikar is currently a Professor (Management) at Harold Pupkewitz Graduate School of Business (HPGSB), Namibia University of Science and Technology, Namibia. Prior to this, she was Head-Scientific Research, with the Ministry of Higher Education CAS-Salalah, Sultanate of Oman, Professor (Strategic Management and Entrepreneurship) at IIIT Pune and BITS India. With a decade-plus of experience in the industry, consultancy, and training, she made a lateral switch to research and academics in 1995. Prof Baporikar holds D. Sc. (Management Studies) USA, Ph.D. (Management), University of Pune INDIA with MBA (Distinction) and Law (Hons.) degrees. Apart from this, she is an external reviewer, Oman Academic Accreditation Authority, Accredited Management Teacher, Qualified Trainer, FDP from EDII, Doctoral Guide, and Board Member of Academic and Advisory Committee in accredited B-Schools. She has to her credit many conferred doctorates, is a member of the international and editorial advisory board, reviewer for Emerald, IGI, Inderscience, Wiley, etc., published numerous refereed papers, and authored books in the area of entrepreneurship, strategy, management, and higher education. 